\section{Small changes, big fuss}

\section{San Franclsco}

After months of public debate, the California Board of Education last week approved new curriculum guidelines that give evolution a more central place in science education. But some last-minute concessions to creationists led to very different accounts of the decision's significance in national and in regional news.

At issue were changes in the wording of the science framework that were negotiated in the past few weeks to guarantee the board's approval. The board vote attracted widespread national attention because California controls about 11 per cent of the country's elementary and junior high school textbook market, and its curriculum guidelines - to which publishers must conform - are considered to be influential in setting national standards. The guidelines also influence high school texts, even though the state does not develop an approved list.

The new framework will take effect from 1992 as part of a curriculum overhaul that California undertakes every seven years. Its implementation follows months of public debate over the place of creationism in the science curriculum, which culminated in a public hearing last October.

After that hearing, some board members insisted on several changes to appease Christian fundamentalists. A sentence was deleted that declared that "there is no scientific dispute that evolution has occurred and continues to occur; this is why evolution is regarded as a scientific fact." And phrases were added to the guidelines stating that "some people reject the theory of evolution purely on the basis of religious faith" and that these "personal beliefs should be respected and not demeaned". These changes were heralded by both the New York Times and $\mathrm{ABC}$ television news as an important victory for creationists, but the San Francisco Chronicle referred to the revised guidelines as "a blueprint for teaching science that emphasizes evolution and relegates creationism to social science classes".

But both sides in the dispute agreed that the last-minute changes were relatively minor. Dan Chernow, chairman of the state's curriculum commission, said that while he was disappointed at the changes, he believed that they are "meaningless". And a spokesman for the California-based Traditional Values Coalition said the group was glad for the modifications but called them "crumbs". The revision leaves largely intact repeated references to evolution's fundamental importance to science. For example, the last six words were added to the statement that "the particular case of 'creation science' or 'scientific creationism' has been thoroughly studied and rejected by the leading scientific societies as qualifying as a scientific explanation". Left unaltered is the declaration that "evolution is the central organizing theory of biology, and has fundamental importance in other sciences as well. It is no more controversial in scientific circles than gravity or electricity is."

Such statements significantly stengthen previous guidelines, which made it clear that evolution must be taught but offered no hints to teachers or school officials on dealing with its role in the controversy surrounding creation theory. The new document addresses this shortcoming, noting in part that teachers "should make it very clear that from the scientific perspective, evolution, like other scientific topics, does not bear on an individual's religious beliefs. Science is not theistic, nor is it atheistic; it does not presuppose religious explanations." Chernow said creation theory should be discussed along with other religious issues, either in the history and social science curriculum or the English and language arts curriculum.

Robert Buderl

\section{ANTARCTIC ASTRONOMY}

\section{Cerenkov telescope for the South Pole}

\section{Washington}

Physicists from Purdue University and the University of Wisconsin at Madison will be travelling south next month to begin a three-year project that will see construction of the first optical telescope, albeit an unconventional one, at the South Pole. An array of ten 1-metre mirrors will be set out on the ice to look for flashes of light caused by ultra-high-energy particles shooting through the upper atmosphere.

For a number of years, researchers from the University of Leeds and the Bartol Institute at the University of Delaware have been operating an air-shower detector at the South Pole (see Nature 340, 192; 1989). This device registers the cascade of debris created by a high-energy particle hitting an atom in the upper atmosphere. The Purdue-Wisconsin group will use an alternative detection method which searches for the Cerenkov radiation emitted by a charged particle moving through a refractive medium such as air.

According to James Gaidos of Purdue, the first goal of the Antarctic project is to demonstrate that optical-quality mirrors will work successfully in the extreme climate. The prototype mirrors for the Purdue-Wisconsin telescope are backed with heating elements to keep their surfaces a few degrees above the air temperature, which should prevent condensation and fogging.

\section{Research for sale}

\section{Sydney}

A DISPUTE at Melbourne University over a proposal for commercially sponsored professorial appointments has cast academic freedom and industrial needs as enemies. The university intends to create a new category of position by which private companies would select researchers and finance a university chair for them. The idea follows the recommendation of a report from a working party headed by the university's vice chancellor, David Penington, which says that corporate-funded appointments are necessary because the university has run out of money to create professorial appointments in new fields.

The sponsored professorial fellows would be appointed at the request of the donor company, without being subject to competitive selection. Nevertheless, Penington says that "for each corporatebacked professorial chair the University council must be satisfied that there are no strings attached. If a company wants to donate funds to the university to take on a particular individual, we would be foolish to appoint anyone else. We will, however, make sure of the calibre of the appointee." But the Federation of Australian University Staff Associations (FAUSA) is unhappy with the university's proposed safeguards. FAUSA believes that people appointed at the donor's behest may be

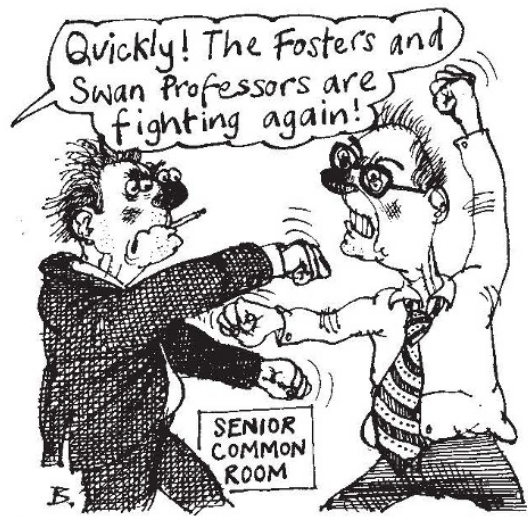

reluctant to participate in research that the donor does not approve.

"If we give up academic independence and criticism for the money these corporations will bring in then the price is too high", says Ralph Hall, president of FAUSA. But Penington disagrees: "We must develop links with industry if research and development in Australia is to flourish."

Tanla Ewing

\section{Correction}

Dr Gerrit Viljoen, the South African Minister for National Education, was professor of Greek at the University of Pretoria before becoming rector of the Rand Afrikaans University in Johannesburg (Nature 342, 8; 1989). 